\title{
Treatment of Corneal Astigmatism at the Time of Cataract Surgery, What Can Be Promised
}

\author{
George Beiko \\ Assistant Clinical Professor, Department of Ophthalmology, McMaster University, Ontario, Canada
}

DOI: http://doi.org/10.17925/EOR.2015.09.02.102

\begin{abstract}
The treatment of corneal astigmatism at the time of cataract surgery is commonplace. Corneal incisional surgery and toric intraocular lenses (IOLS) are routinely utilised; the role of each modality is understood and defined. Although technological advances have been made in the assessment of the cornea and in the execution of the treatment options, recent innovations in toric IOL designs may be more significant for the comprehensive ophthalmologist.
\end{abstract}

\section{Keywords}

Cataract surgery, corneal astigmatism, toric IOLS

Disclosure: George Beiko has nothing to disclose in relation to this article. No funding was received in the publication of this article. Open Access: This article is published under the Creative Commons Attribution Noncommercial License, which permits any non-commercial use, distribution, adaptation and reproduction provided the original author(s) and source are given appropriate credit.

Received: 27 November 2015 Published Online: 21 December 2015 Citation: European Ophthalmic Review, 2015;9(2):102-3 Correspondence: George Beiko, 180 Vine St, Ste 103, St Catharines, Ontario L2R 7P3, Canada E: georgebeiko@hotmail.com

Cataract surgery offers the ophthalmic surgeon an opportunity to treat corneal astigmatism. However, the question remains, what is reasonably possible and what is needed to attain this possibility?

As an initial step, the question needs to be asked, how much astigmatism is significant? Employing adaptive optics and bench top studies, it has been shown that there is little visual benefit in reducing astigmatism to less than $0.50 \mathrm{D} .{ }^{1}$ In terms of optical quality $1.00 \mathrm{D}$ or greater of astigmatism results in decreased vision below 20/20 in $50 \%$ of patients (Steve Schallhorn, review of 4,956 premium intraocular lens [IOL] cases, personal communication). However, the significance of residual astigmatism is probably best expressed in terms of when patients would be willing to undergo another procedure for correction of that astigmatism; $90 \%$ of patients are unwilling to have further surgical intervention unless the astigmatism is greater than $1.00 \mathrm{D}^{2}$ Thus, the majority of surgeons will offer management of astigmatism to patients with 0.75 to $1.00 \mathrm{D}$ of corneal astigmatism. ${ }^{3}$

Approximately $40 \%$ of patients coming to cataract surgery have greater than 1.0 D of corneal astigmatism and could be considered as candidates for intervention.

Accuracy in the treatment of astigmatism requires that the contribution of posterior corneal curvature and the drift of the astigmatism postoperatively with time be considered. Currently, the recommendation is to target an outcome with a small degree of with-the-rule astigmatism ( 0.25 to $0.50 \mathrm{D}$ ) when managing corneal astigmatism correction; this result will adequately compensate for both the posterior corneal astigmatism and any drift with time in the majority of cases. ${ }^{4}$

Management options for corneal astigmatism include toric IOLS and incisional surgery. Incisional techniques range from cataract wound incision construction and placement, opposite clear corneal incisions, limbal relaxing incisions and astigmatic keratotomy. Comparing incisional techniques to toric IOLS, outcomes were similar in patients with corneal astigmatism up to $2 \mathrm{D}$. However, if the corneal astigmatism is greater than $2.25 \mathrm{D}$, toric IOLs result in better outcomes. ${ }^{5}$

Although femtosecond lasers are touted as being more accurate in the performance of incisional correction of astigmatism, studies have found that the outcomes are not as dramatic. ${ }^{6-11}$ Femtosecond corneal incisions are effective for astigmatism less than $2.0 \mathrm{D}$ and, although they are statistically better, femtosecond lasers are clinically only $5 \%$ more effective than manual incisions..$^{12}$ Intrastromal femtosecond laser incisions are minimally less effective than femtosecond astigmatic keratotomy, and can be used up to $1.50 \mathrm{D}$.

The most common choice for ophthalmologists for correcting astigmatism continue to be toric IOLS. ${ }^{13}$ When determining the power of a toric IOL, preoperative assessment with optical biometry and either corneal topography or tomography is essential. The use of intraoperative aberrometry has not shown any definitive advantage in this respect. Toric calculators allow for more accurate assessment of the amount of astigmatism to be corrected. Using a calculator based on the Holladay 1 formula, instead of a fixed ratio toric calculator, can improve the accuracy by up to $0.44 \mathrm{D}$, especially in high- and Iow-power IOLs. ${ }^{14}$

For alignment of toric IOLS, conventional marking systems and digital systems have been evaluated. Using conventional marking, it has been found that the error in one-piece acrylic toric IOL alignment is approximately $5^{\circ}$, but may be higher than $10^{\circ}$ in $3 \%$ of patients. The values are much higher with silicone plate haptic toric IOLS, 6-9 ${ }^{\circ}$ and $20 \%$, respectively. ${ }^{15,16}$ Comparing a one-step conventional marking 
system using a pendulum marker to a two-step digital system with both iris and limbal registration, the digital system was significantly more accurate $(p=0.003) ; 2.4^{\circ} \pm 1.96^{\circ}$ for the digital system versus $4.33^{\circ} \pm 2.72^{\circ}$ for the one-step conventional marking system. ${ }^{17}$ Similarly, intraoperative aberrometry has been reported to yield significantly more accurate outcomes in terms of cylinder axis than conventional marking systems. 18,19

Recent developments in toric IOL design have made significant advances in improving the ability to attain desired outcomes. The Precizon Toric IOL (Ophtec, Groningen, The Netherlands) has a proprietary design that allows the lens to be $100 \%$ more forgiving of misalignment (Eric Mertens, personal communication). The Symfony lens (Abbott Medical
Optics, Santa Ana, US), due to its design, allows for compensation of approximately 1.25 D of astigmatism in its spheric form; the toric version should theoretically also have this additional ability to be tolerant of power and alignment error.

Currently, the comprehensive ophthalmologist has the ability and confidence to successfully correct stable regular corneal astigmatism at the time of cataract surgery, using tools that should be at his disposal. Digital technology does provide some evidence of improved outcomes. However, by employing optical biometry, corneal topography, a toric calculator, conventional marking systems and one of the recently developed novel designs of tolerant toric IOLs, comparable outcomes to those attained with more expensive technology can be promised.
1. Chen L, Artal P, Gutierrez D, Williams DR, Neural compensation for the best aberration correction, J Vis, 2007:7:1-9.

2. Bradley MJ, Coombs J, Olson RJ, Analysis of an approach to astigmatism correction during cataract surgery, Ophthalmologica, 2006:220:311-6.

3. Leaming D, 2013 Survey of ESCRS Members: Results and Trends. Presented at ESCRS Annual Meeting, London, UK, 2014. Koch DD, Jenkins RB, Weikert MP, et al., Correcting astigmatism with toric intraocular lenses: effect of posterior corneal astigmatism, J Cataract Refract Surg, 2013;39:1803-9. Poll JT, Wang L, Koch DD, Weikert MP, Correction of astigmatism during cataract surgery: toric intraocular lens compared to peripheral corneal relaxing incisions, $J$ Cat Refract Surg, 2011;27:165-71.

6. Bahar I, Levinger E, Kaiserman I, et al., IntraLase-enabled astigmatic keratotomy for postkeratoplasty astigmatism, Am J Ophthalmol, 2008;146:897-904

7. Hoffart L, Proust H, Matonti F, et al., Correction of postkeratoplasty astigmatism by femtosecond laser compared with mechanized astigmatic keratotomy, Am
Ophthalmol, 2009;147:779-87.

8. Wetterstrand O, Holopainen JM, Krootila K, Treatment of postoperative keratoplasty astigmatism using femtosecond laser-assisted intrastromal relaxing incisions, $J$ Refract surg 2013;29:378-82.

9. Hjortdal JO, Ehlers N, Paired arcuate keratotomy for congenital and post-keratoplasty astigmatism, Acta congenital and post-keratoplasty astign

10. Poole TR, Ficker LA, Astigmatic keratotomy for post-keratoplasty astigmatism, I Cataract Refract surg, 2006;32:1175-9.

11. Hovding G, Transverse keratotomy in postkeratoplasty astigmatism, Acta Ophthalmol (Copenh), 1994;72:464-8.

2. Newsome T, Femtosecond AK, How to Make the Cut, Review of Ophthalmology, 2013. Available at: http://www. reviewofophthalmology.com/content///2355/c/40139/ (accessed 3 December 2015).

13. ASCRS Clinical Survery 2014 Findings, Modernizing cataract surgery: Navigating success with toric multidfocal IOLS, Eyeworld, September 2015, supplement.
14. Canovas C, Piers P, Holladay JT, Comparison between cylinder IOL power calculations. Presented at: ESCRS Annual Meeting, Milan, 11 September 2012

15. Visser $\mathrm{N}$, Berendschot $\mathrm{TT}$, Bauer $\mathrm{NJ}$, et al., Accuracy of toric intraocular lens implantation in cataract and refractive surgery, I Cataract Refract Surg, 2011;37:1394-402.

16. Visser N Bauer N1 Nuijts RM, Toric intraocular lenses: historical overview, patient selection, IOL calculation, surgical techniques, clinical outcomes, and complications, J Cataract Refract Surg, 2013:39:624-37.

17. Elhofi AH, Helaly HA. Comparison between digital and manual marking for toric intraocular lenses: A randomized trial, Medicine (Baltimore), 2015;94:e1618.

18. Faulkner $\mathrm{A}$, Randomized prospective comparison of toric $\mathrm{IOL}$ power and axis determination by intraoperative aberrometry vs toric calculator. Presented at: ESCRS Annual Meeting, Barcelona, 8 September 2015

19. Hatch KM, Woodcock EC, Talamo JH, Intraocular lens power selection and positioning with and without intraoperative aberrometry, J Refract Surg, 2015:31:237-42. 